\title{
Preparedness for the Smoking Cessation Role among Health Sciences Students in Kuwait
}

\author{
Mohammad Waheedi Aisha M. Al-Tmimy Hannes Enlund \\ Department of Pharmacy Practice, Faculty of Pharmacy, Health Sciences Centre, Kuwait University, Jabriya, Kuwait
}

\section{Key Words}

Smoking cessation - Students of health professions •

Questionnaires

\begin{abstract}
Objective: Our aim was to assess students' preparedness for the smoking cessation role after a teaching module on tobacco cessation and to assess the relationship between smoking status and preparedness. Methods: Pharmacy students attended a 4-hour module on the role of health professionals in smoking cessation based on the $R x$ for Change training program. Two years after the first introduction of the module, a questionnaire on preparedness and smoking status was filled in by 64 pharmacy students who had attended the module and 243 students from other health sciences that had not been exposed to the module. Results: Preparedness scores for the smoking cessation role for pharmacy students were significantly higher (mean $=19.5, \mathrm{n}=63$ ) for the nonsmoking pharmacy students compared to other nonsmoking students in medicine (mean $=16.2, \mathrm{n}=149$ ), dentistry (mean $=16.1, \mathrm{n}=40$ ) and physical therapy (mean $=14.9, \mathrm{n}=$ 16) $(p=0.009)$. The smoking prevalence was $3 \%$ among all females and 31\% among all males. Smoking students were significantly less likely $(p=0.031)$ to agree that it is their professional responsibility to help patients quit smoking. Conclusion: Significant and long-lasting differences in students' perception of preparedness for the smoking cessation role
\end{abstract}

based on exposure to a short teaching module were demonstrated. Furthermore, our results support previous findings that smoking compromises attitude towards helping smokers to quit.

Copyright $\odot 2011$ S. Karger AG, Base

\section{Introduction}

Tobacco kills 5.4 million people a year and unless urgent action is taken, this will increase to 8 million a year by 2030 , with $80 \%$ of those deaths occurring in developing countries [1]. Health professionals can have an important role in countering tobacco use; an advice as brief as 3 min can significantly increase the chances of success in quitting smoking compared to nonintervention [2]. One intervention, composed of screening for smoking, brief advice and offering medications, has been judged to be one of the top 3 most valuable clinical preventative services offered in medical practice [3]. Hence, encouraging the involvement of health professionals has been a key element in initiatives led by the World Health Organization (WHO) in counteracting tobacco use. The 2008 WHO report on the global tobacco epidemic recommended offering help to every tobacco user to quit as 1 of the 6 policies that have been proven to reduce tobacco use and that every country should put into practice [1].

\section{KARGER}

Fax +4161306 1234

E-Mail karger@karger.ch

www.karger.com
(C) 2011 S. Karger AG, Basel

1011-7571/11/0203-0237\$38.00/0

Accessible online at:

www.karger.com/mpp
Dr. Mohammad Waheedi

Faculty of Pharmacy

Health Sciences Centre, Kuwait University

PO Box 24923, Safat 13110 (Kuwait)

Tel. +965 2498 6852, Fax +965 2498 6840, E-Mail m.waheedi@ku.edu.kw 
Despite the emphasis on their role, health professionals do not usually intervene with smokers. In a 1997 American study, only $16 \%$ of the identified smokers received smoking cessation advice from physicians [4], which increased somewhat to $27 \%$ in 2009 [5]. The incidence of tobacco counseling in developing countries is unknown; however, only $10 \%$ of the physicians in Indonesia and 32\% in India asked about tobacco use [6].

The disinclination of health professionals to intervene derives from several causes, including their inadequate preparation and the pervasiveness of smoking among health care providers in many parts of the world. A report released by the $\mathrm{WHO}$ on the role of health professionals in tobacco control named a lack of knowledge and skills as the number one barrier to health professionals' involvement in tobacco control activities [7]. Knowledge and skills related to smoking cessation are assumed to be taught in professional schools, but surveys have shown repeatedly that curricula are inadequate [8-14]. Continuous smoking among health professionals (e.g. $45 \%$ in China, 38\% in Kuwaiti males [15]) and students of health professions (e.g. 44\% in Spain, 51\% in Japan [16] and 31\% in Jordanian males [17]) is another impediment. Although it is obvious that advice from a health professional who smokes is less credible, a further alarming implication is the finding that health professionals who smoke are less willing to encourage clients who smoke to quit $[18,19]$.

Kuwait is an example of a country with a high prevalence of smoking, even among its health care professionals [15], with little experience of antitobacco activities. In this paper we described our experience training a group of pharmacy students to take an interventionist role with smokers and compared their preparedness for this role with other students of the only health sciences institution in Kuwait. We sought to answer the following 2 questions. First, is there a difference in preparedness between the pharmacy students who attended our smoking cessation module and the other students of health professions who did not attend it? And second, is there a difference in preparedness between smoking and nonsmoking students?

\section{Subjects and Methods}

\section{The Teaching Module}

In early 2006 we developed a 4-hour module on smoking cessation and incorporated it as required coursework for the second semester for third-year pharmacy students in the Kuwait University Health Sciences Centre (table 1). It was delivered to the stu-
Table 1. The components of the 4-hour teaching module to the pharmacy students

\begin{tabular}{ll}
\hline $\begin{array}{l}\text { Delivery } \\
\text { method }\end{array}$ & Component \\
\hline $\begin{array}{l}\text { Lecture 1 } \\
(1 \mathrm{~h})\end{array}$ & $\begin{array}{l}\text { Epidemiology of smoking and benefits of quitting (15 min) } \\
\text { Nicotine pharmacology and principles of addiction (5 min) } \\
\text { Pharmacological products for cessation (40 min) }\end{array}$ \\
\hline $\begin{array}{l}\text { Self-reading } \\
\text { handouts }\end{array}$ & $\begin{array}{l}\text { Fagerström instrument for nicotine dependence (1 page) } \\
\text { The } 5 \text { A's counseling guide sheet (1 page) } \\
\text { Cognitive and behavioral strategies for quitting (1 page) } \\
\text { Withdrawal symptoms information sheet (1 page) }\end{array}$ \\
\hline $\begin{array}{l}\text { Pharmacological product guide (2 pages) } \\
(1 \mathrm{~h})\end{array}$ & $\begin{array}{l}\text { The } 5 \text { A's method of assisting patient with quitting (50 min) } \\
\text { Interviews with smokers videos (10 min) }\end{array}$ \\
\hline $\begin{array}{l}\text { Workshop } \\
(2 \mathrm{~h})\end{array}$ & $\begin{array}{l}\text { Group assignment writing responses and recommendations } \\
\text { to 2 patient scenarios, including pharmacological } \\
\text { interventions (90 min) } \\
\text { Counseling a hypothetical patient (30 min) }\end{array}$ \\
\hline
\end{tabular}

dents only once for 2 days during the same week approximately at midsemester. The first day featured a 1-hour lecture and the second another hour of lecture with an additional 2-hour workshop. The module was based on materials provided by the $R x$ for Change tobacco cessation training program [20], a curriculum that was developed from collaborative work among 3 schools of pharmacy in the USA to provide state-of-the-art knowledge and skills for assisting patients to quit smoking. The program is disseminated free of charge to those interested in teaching clinicians or students of any health profession and emphasizes counseling as well as pharmacotherapy to treat tobacco dependence. The teaching strategies include reading materials for students, slides with instructor notes, videos of trigger scenarios, case scenarios for role playing and counseling sessions. The program is usually implemented in $6-8 \mathrm{~h}$ and has been shown to be effective in improving students' perceived abilities and confidence in providing tobacco cessation counseling to patients [21] and improving psychiatry residents' cessation counseling behaviors [22].

\section{Population and Sample Recruitment}

Approval to conduct the study was obtained from the ethics committee of the Health Sciences Centre at Kuwait University. The population targeted was fourth- and fifth-year pharmacy students (88) who had attended the teaching module previously (during their third study year) and we compared them with medical students (470) from the fourth to the seventh year, dentistry students in the fifth and sixth year (71), and physical therapy students in the fourth year (27). Data were collected over 40 days during March and April of 2008.

The students were invited to fill in a questionnaire while they were at their classes and instructed to leave the completed questionnaires with a designated person in the class. Students who had experiential training during the semester were approached at their practice sites and invited to participate. Experiential training students often were not found at their sites, therefore a 'snowball' sampling method [23] was applied to recruit these students, 
Table 2. Sample characteristics and comparison based on current smoking status

\begin{tabular}{|c|c|c|c|c|}
\hline \multirow[t]{2}{*}{ Parameter } & \multirow{2}{*}{$\begin{array}{l}\text { Overall } \\
\text { sample } \\
(n=307)\end{array}$} & \multicolumn{3}{|c|}{ Current smoking status } \\
\hline & & $\begin{array}{l}\text { smoking } \\
(\mathrm{n}=39)\end{array}$ & $\begin{array}{l}\text { nonsmoking } \\
(\mathrm{n}=268)\end{array}$ & $\begin{array}{l}\mathrm{p} \\
\text { value }\end{array}$ \\
\hline Mean age $\pm S D$, years & $23 \pm 1.5$ & $23.1 \pm 1.9$ & $22.8 \pm 1.4$ & 0.217 \\
\hline Gender & & & & $<0.001$ \\
\hline Female & $200(65)$ & $6(3)$ & $194(97)$ & \\
\hline Male & $107(35)$ & $33(31)$ & $74(69)$ & \\
\hline Academic program & & & & 0.001 \\
\hline Medicine & $182(59)$ & $33(18)$ & $149(82)$ & \\
\hline Dentistry & $41(13)$ & $1(2)$ & $40(98)$ & \\
\hline Pharmacy & $64(21)$ & $1(2)$ & $63(98)$ & \\
\hline Physical therapy & $20(7)$ & $4(20)$ & $16(80)$ & \\
\hline
\end{tabular}

Figures in parentheses are percentages. perceived professional responsibility: 'it is my professional responsibility to help smokers (or water pipe users) quit'. Responses to these items were on a 5-point Likert scale from 'strongly disagree' to 'strongly agree'.

\section{Statistical Analysis}

The data were analyzed using SPSS 16.0 software. Items were described by frequency distributions and crosstabulations. Pearson's $r$ and $\chi^{2}$ statistics were used to test for statistically significant relationships among various measures. A preparedness scale was produced by adding the scores of the 5 attitudinal items (Cronbach's $\alpha=0.78$ ). A t test was performed to test for the effect of smoking on this scale as a dependent variable. Since smoking was negatively associated with measures of preparedness and since smokers were disproportionately represented among the academic programs, we excluded students who were smokers in the analysis relating academic programs to preparedness. Here, a 1-way ANOVA test was used with a post-hoc Scheffe test to compare academic programs on the preparedness scale.

\section{Results}

\section{Smoking Behaviors}

whereby referrals from initial contacts were used to generate additional contacts. Of the 656 representing the population, 337 were reachable using our recruitment methods and were invited to participate. Of the 337 students who were asked to participate, 307 returned usable responses; a response rate of about $91 \%$. The sample had an average age of $23 \pm 1.5$ years and was composed mostly of females: 200 , and students in medicine: 182, dentistry: 41, pharmacy: 64 and physical therapy: 20 .

\section{Instrument}

We used a self-administered modified questionnaire with 23 items adapted from a previous study that involved students of the health professions in the USA [24]. The items were changed for the local context for water pipe smoking and the absence of chewing tobacco use in Kuwait. The questionnaire went through 2 stages of pretesting and piloting. First, to assess the appropriateness and readability of the items, 8 students were asked to read the survey in front of the researchers and voice any encountered ambiguities. Several changes were made to improve the content and the overall format for easier administration. The final instrument was pilot tested with 19 dentistry and 18 medical students, who were later included in the final sample since no further revisions were made.

The survey instrument contained 19 closed-ended and 4 openended items. The open-ended ones were intended to elicit the respondent's age and, if applicable, his/her age when (s)he started to smoke, the frequency of smoking and amounts smoked. The closed-ended items collected data about professional program, gender, current smoking status, types of tobacco, smoking history, readiness to quit and 6 items to measure attitudes relating to preparedness to take the role of smoking cessation. The 6 attitudinal items included 1 to measure perceived curricular content: 'my professional program had course content about my role in helping tobacco-using patients quit', 2 items to measure perceived adequacy of preparation: 'my program adequately prepared me to help smokers (or water pipe users) quit', and 2 items to measure
The prevalence of smoking among females was $3 \%$ and among males $31 \%$ (table 2). Within academic programs, the prevalence of smoking was $33(18 \%)$ in medicine, 1 (2\%) in dentistry, $1(2 \%)$ in pharmacy and $4(20 \%)$ in physical therapy $(\mathrm{p}=0.001)$.

On average, the age at which students started smoking was $17.5 \pm 2.3$ years, with half of the smokers starting before 18 years of age. Of those currently smoking, 8 (20\%) smoked only water pipe, 15 (39\%) smoked only cigarettes and/or cigars, and 16 (41\%) smoked both cigarettes and water pipe. No other types of tobacco use were reported. Among the cigarette smokers, $12(40 \%)$ reported smoking $<10$ cigarettes per day, 10 (33\%) 10-20 cigarettes and $8(27 \%)>20$ cigarettes per day.

\section{Preparedness for Smoking Cessation Role}

Only nonsmoking students $(\mathrm{n}=268)$ were included in the analysis investigating the effect of programs on preparedness. Overall, 115 (43\%) of the nonsmoking sample agreed that their program had course content related to the smoking cessation role, while only $72(27 \%)$ agreed that they were adequately prepared to help smokers and 56 (21\%) agreed that they were adequately prepared to help water pipe users. However, the majority of the nonsmoking students agreed that it is their professional responsibility to help smokers quit $(\mathrm{n}=220,82 \%)$ and to help water pipe users quit $(\mathrm{n}=206,77 \%)$.

When pharmacy students were compared with students of the other programs on the 5 attitudinal mea- 
Fig. 1. Medical students' agreement with preparedness measures by smoking status.

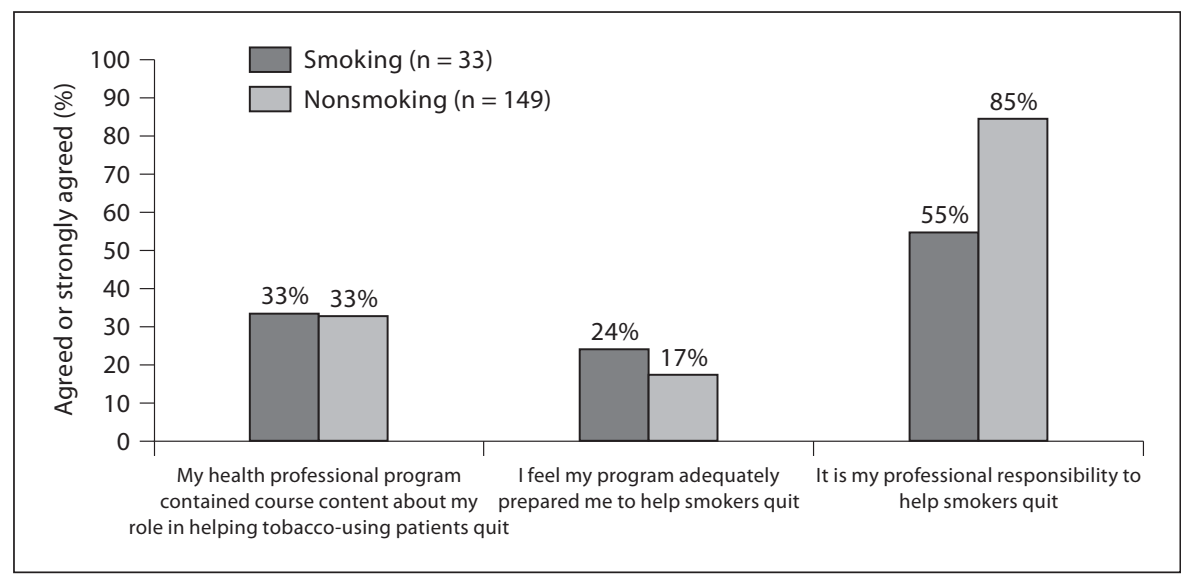

Table 3. Nonsmoking students' agreements with measures of preparedness by academic program

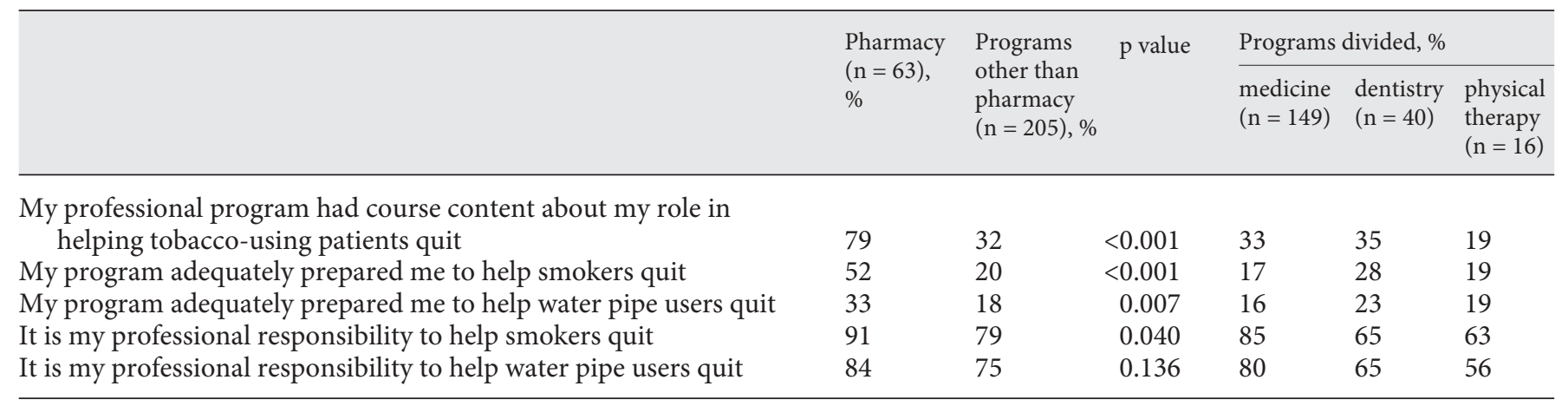

sures, statistically significant differences were found for 4 of the 5 items (table 3). The 1-way ANOVA using the preparedness scale resulted in a significant main effect for academic program $(\mathrm{p}=0.009)$. The post-hoc Scheffe test showed that the pharmacy group had significantly higher scores $($ mean $=19.5)$ than medicine $($ mean $=16.2$, $\mathrm{p}<0.001)$ and dentistry (mean $=16.1, \mathrm{p}<0.001)$. No statistical differences were found between students of medicine and dentistry on this scale at the 0.05 level of significance. Physical therapy was not included in the posthoc tests because the nonsmoking sample was too small $(\mathrm{n}=16$, mean $=14.9)$, which led to 1 comparison group with $<2$ cases.

\section{Attitude Differences between Smoking and \\ Nonsmoking Students}

A t-test between smoking and nonsmoking groups resulted in significantly higher scores for nonsmoking $($ mean $=16.9)$ than smoking students $($ mean $=15.4, \mathrm{p}=$
0.031). Since medicine had the majority of the smoking students in the sample (33 out of 39), a more detailed analysis of attitudes based on smoking status was conducted including only the medical students (fig. 1). The nonsmoking medical students were more likely $(85 \%)$ to agree that it is their professional responsibility to help smokers than the smoking medical students $(55 \%, \mathrm{p}=$ 0.001). Smoking and nonsmoking students were not different in their agreement about the program content or about the adequacy of preparation.

\section{Discussion}

The attitudes of pharmacy students who participated in our module on the professional role of smoking cessation were much more favorable than those of medical, dentistry or physical therapy students who did not participate in the module. These findings suggest that the 
module we used can improve the preparedness of students for the smoking cessation role. This is especially important considering the brief amount of time spent, only $4 \mathrm{~h}$, on lectures and workshops. Also important is the fact that the survey was administered 1-2 years after the module, suggesting that the effect on attitude is longlasting.

The attitude scores of our sample were generally lower than the scores reported by Fried et al. [24], who used similar attitudinal items in a sample of students of health professions in the USA. For example, about 2 thirds of the students in the American study agreed with the statement: 'my professional programs had course content about the role of smoking cessation' in comparison to less than half in our study. Within the subgroups, all pharmacy and medical students in the US study [24] agreed with this item while the agreement in our study was $80 \%$ in pharmacy and only $33 \%$ in medicine.

With the exception of pharmacy, the lower scores in our sample are consistent with research reporting inadequacy of tobacco curricula in many parts of the world. A series of studies surveying 42 countries in the early 1990s warned about the seriousness of the deficiency in tobacco education and recommended urgent changes [811]. A worldwide survey of medical curricula published in 1998 found that all schools that reported absence of teaching about tobacco were in Africa, Asia, Europe and South America [12]. No school in the Middle East region reported having a specific module for tobacco. More recently, 2 studies confirmed the persistence of this problem even in developed countries; no mention of smoking or smoking cessation was found in the published curriculum of $42 \%$ of the UK's medical schools [13]. The other study surveyed medical students in Germany and the UK and found them to be lacking in basic knowledge about the consequences of smoking and cessation methods [14].

The second major finding of our study was the high prevalence of smoking among medical students, who were reluctant to take an interventionist role. The 31\% prevalence of smoking in male medical students identified in this study is close to the $35 \%$ reported for the general male population of Kuwait [25]. Although studies have been reporting a reduction in prevalence of smoking among physicians to near elimination in several countries (e.g. 2-3\% in the USA, Australia and UK), higher rates still exist in some developed countries (up to 25\% in Italy, France and Japan) and even higher rates in other countries such as China: $45 \%$, Kuwait: $38 \%$ and the United Arab Emirates: 36\% [15]. Within medical students, a review article reported similar variations among differ-

Preparedness for the Smoking Cessation Role ent countries with smoking rates of $2-3 \%$ in Australia and the USA, and higher rates in countries like Spain (44\%), Hungary (36\%), Japan (51\% among males) and Saudi Arabia (33\% among males) [16]. Similarly, among dental students, the lowest smoking rates were found in Australia, Brazil, Canada, the UK and the USA, while higher rates were observed in countries such as Greece, Serbia, Romania, Hungary [26] and Jordan [17]. Smoking is also common among nursing and pharmacy students and its prevalence varies depending on the country of study $[27,28]$.

The students in our sample who smoke harbor a more negative attitude towards helping patients who smoke quit compared to students who are nonsmokers. Similar results were found in a study of medical students in Finland; nonsmokers were more likely to plan to intervene with patients who smoke and more likely to believe that it is the doctor's responsibility to convince people to quit smoking [29]. Within health professionals, several studies have documented a link between their smoking habits and readiness to help smokers. For example, a study of health professionals in an Italian hospital found negative correlations between smoking habits and the attitude of health staff toward patient counseling about smoking [18]. Only $50 \%$ of the Greek physicians who smoked reported involvement in smoking cessation counseling compared to $100 \%$ of the nonsmoking group [19]. A recent survey study in North America, Western Europe and Asia also found physicians who are nonsmokers to hold stronger beliefs about the adverse effects of smoking and engage in more clinical activities to assist smokers to quit than physicians who smoke [30].

The limitations of our study were due to its cross-sectional design. Since we did not measure attitudes of the pharmacy students before exposure to the module, we cannot be certain about the cause and effect relationship. However, our attempts to compare other academic programs provide support for the evidence. Another limitation of our study was that it described only attitudes rather than actual behavior of students. Although the pharmacy students reported favorable attitudes, we do not know whether they will differ in their counseling behavior in practice. Although the vast majority of those we were able to reach responded to our survey, our sample was not randomly selected and self-selection by availability may contribute to bias.

Important areas for future research include the study of the actual counseling behavior of students during their experiential training or after they graduate and enter practice. Another is the study of crosscultural differences 
that may affect the attitudes of smoking health staff or students towards participating in smoking cessation role.

\section{Implications}

Considering the documented deficiencies in curricula and the improvement in preparedness achieved in our study, an implication can be drawn for strategies needed to infuse health sciences education with smoking cessation content, especially in countries with a clear need for antismoking programs and high smoking prevalence. The availability of effective smoking cessation curricula such as $R x$ for Change can serve as an efficient cost-saving approach to help disseminate evidence-based practices to schools in these countries. The instructor's expertise regarding the subject matter is compensated for by the ready-to-deliver format of the program. Inhouse preparation of such material would require long hours of training and considerable investment of resources; still with no assurance of quality control. We implemented this program with only small changes to include country's statistics and replaced discussion of chewing tobacco with one about water pipe smoking. We did not identify the factors that contributed to improvements in students' preparedness; however, we speculate that it has to do with the high quality of material with the variety of learning methods such as lectures, videos and role play.
Another implication of our findings is related to the high prevalence of smoking among students who were found to be less likely to intervene with smokers in the future. It has been suggested that the smoking status of the health professionals can predict the effectiveness of any antismoking campaign within a country [31]. Therefore, educators and policymakers need to direct attention to the smoking status of students to avoid compromising their future antismoking role. Attempts should be made to reduce smoking among students of the health care profession. Policies that discourage smoking among students should be initiated and enforced throughout the students' length of stay in the school; for example, schools should offer smoking cessation programs for students who smoke and reward those who participate in such programs.

\section{Conclusion}

The findings showed significant differences in students' perceptions of preparedness for the smoking cessation role based on exposure to a brief and relatively simple teaching module. Also, there was a relatively high rate of prevalence of smoking within future clinicians, which may be of concern considering their potential role in smoking cessation.

\section{References}

1 World Health Organization: WHO report on the global tobacco epidemic 2008. http:// www.who.int/tobacco/mpower/mpower_report_full_2008.pdf. (accessed 1 May 2009).

$\checkmark 2$ Fiore MC: Treating tobacco use and dependence: an introduction to the US Public Health Service Clinical Practice Guideline. Respir Care 2000;45:1196-1199.

3 Maciosek MV, Coffield AB, Edwards NM, Flottemesch TJ, Goodman MJ, Solberg LI: Priorities among effective clinical preventive services: results of a systematic review and analysis. Am J Prev Med 2006;31:52-61.

-4 Jaén CR, Stange KC, Tumiel LM, Nutting P: Missed opportunities for prevention: smoking cessation counseling and the competing demands of practice. J Fam Pract 1997;45: 348-354.

5 Sonnenfeld N, Schappert S, Lin S: Racial and ethnic differences in delivery of tobacco-cessation services. Am J Prev Med 2009;36:2128.

6 Nichter M: Introducing tobacco cessation in developing countries: an overview of Project Quit Tobacco International. Tob Control 2006;15:12-17.
7 WHO Tobacco Free Initiative: The role of health professionals in tobacco control. World No Tobacco Day 2005. http://www. who.int/entity/tobacco/resources/publications/wntd/2005/bookletfinal_20april.pdf (accessed 1 May 2009).

${ }_{8}$ Tessier JF, Freour P, Nejjari C, Belougne D, Crofton J: Smoking behaviour and attitudes of medical students towards smoking and anti-smoking campaigns: a survey in $10 \mathrm{Af}-$ rican and Middle Eastern countries. Tob Control 1992;1:95-101.

-9 Tessier JF, Freour P, Nejjari C, Belougne D, Crofton J: Smoking behaviour and attitudes towards smoking of medical students in Australia, Japan, USA, Russia, and Estonia. Tob Control 1993;2:24-29.

10 Tessier JF, Freour P, Belougne D, Crofton J, tobacco and health committee of the international union against tuberculosis and lung diseases: Smoking habits and attitudes of medical students towards smoking and antismoking campaigns in nine Asian countries. Int J Epidemiol 1992;21:298-304.
1 Tessier JF, Freour P, Crofton J, Kombou L: Smoking habits and attitudes of medical students towards smoking and antismoking campaigns in fourteen European countries. Eur J Epidemiol 1989;5:311-321.

12 Richmond RL, Debono DS, Larcos D, Kehoe L: Worldwide survey of education on tobacco in medical schools. Tob Control 1998;7:247252.

13 Roddy E, Rubin P, Britton J: A study of smoking and smoking cessation on the curricula of UK medical schools. Tob Control 2004;13: 74-77.

14 Raupach T, Shahab L, Baetzing S, Hoffmann B, Hasenfuss G, West R, Andreas S: Medical students lack basic knowledge about smoking: findings from two European medical schools. Nicotine Tob Res 2009;11:92-98.

15 Smith DR, Leggat PA: An international review of tobacco smoking in the medical profession: 1974-2004. BMC Public Health 2007;7:115

16 Smith DR, Leggat PA: An international review of tobacco smoking among medical students. J Postgrad Med 2007;53:55-62. 
17 Alomari Q, Barrieshi-Nusair K, Said K: Smoking prevalence and its effect on dental health attitudes and behavior among dental students. Med Princ Pract 2006;15:195-199.

-18 Nardini S, Bertoletti R, Rastelli V, Ravelli L, Donner CF: Personal smoking habit and attitude toward smoking among the health staff of a general hospital. Monaldi Arch Chest Dis 1998;53:74-78.

19 Polyzos A, Gennatas C, Veslemes M, Daskalopoulou E, Stamatiadis D, Katsilambros $\mathrm{N}$ : The smoking-cessation promotion practices of physician smokers in Greece. J Cancer Educ 1995; 10:78-81.

20 Hudmon KS, Corelli RL, Chung E, Gundersen B, Kroon LA, Sakamoto LM, Hemberger KK, Fenlon C, Prokhorov AV: Development and implementation of a tobacco cessation training program for students in the health professions. J Cancer Educ 2003;18:142-149.
21 Hudmon KS, Kroon LA, Corelli RL, Saunders KC, Spitz MR, Bates TR, Liang D: Training future pharmacists at a minority educational institution: evaluation of the Rx for Change tobacco cessation training program. Cancer Epidemiol Biomarkers Prev 2004; 13 : 477-481.

22 Prochaska JJ, Fromont SC, Leek D, Hudmon KS, Louie AK, Jacobs MH, Hall SM: Evaluation of an evidence-based tobacco treatment curriculum for psychiatry residency training programs. Acad Psychiatry 2008;32:484492.

23 Churchill GA: Marketing Research: Methodological Foundations, ed 7. Fort Worth, Dryden Press, 1999.

24 Fried JL, Reid BC, DeVore LE: A comparison of health professions student attitudes regarding tobacco curricula and interventionist roles. J Dent Educ 2004;68:370-377.

25 World Health Organization: Country profiles: Kuwait. http://www.emro.who.int/emrinfo/index.asp?Ctry=kuw\#Demographic (accessed May 15, 2009).

26 Smith DR, Leggat PA: An international review of tobacco smoking among dental students in 19 countries. Int Dent J 2007;57: 452-458.
27 Smith DR: A systematic review of tobacco smoking among nursing students. Nurse Educ Pract 2007;7:293-302.

28 Silva V, Chauvin J, Jones N, Warren W, Asma S, Pechacek T: Tobacco use and cessation counseling - Global Health Professionals Survey pilot study, 10 countries. MMWR Morb Mortal Wkly Rep 2005;54:505-509.

29 Toriola AT, Myllykangas MT, Barengo NC: Smoking behaviour and attitudes regarding the role of physicians in tobacco control among medical students in Kuopio, Finland, in 2006. CVD Prev Control 2008;3:53-60.

30 Pipe A, Sorensen M, Reid R: Physician smoking status, attitudes toward smoking, and cessation advice to patients: an international survey. Patient Educ Couns 2009;74:118123.

31 Davis R: When doctors smoke. Tob Control 1993;2:187-188. 